\title{
EL TERRITORIO COMO PUENTE ENTRE LA CULTURA Y LA POLÍTICA, PARTE I. TRAYECTORIA INSTITUCIONAL DE FEDERICO A. DAUS 1922-1957
}

\author{
Marcelo E. Lascano ${ }^{1}$ \\ Susana I. Curto ${ }^{2}$
}

\begin{abstract}
Resumo: Se presenta una cronología de la trayectoria de Federico Daus a través de las instituciones a las que perteneció y de las personas con quienes se formó y trabajó. Se contó con información primaria y secundaria. Se caracteriza su paso por la Universidad de Buenos Aires, la Universidad de La Plata, los cambios ocurridos en estas instituciones con el advenimiento del peronismo, y se describe brevemente su actuación posterior. Inicialmente se desenvuelve en un ámbito ligado a la arqueología, desarrollando en paralelo su interés por lo territorial. Con la llegada del peronismo su carrera se encauza dentro del contexto de separación entre antropología y geografía. En esta transición Daus asume un cargo en el Ministerio de Educación de la Nación, ajeno a los estudios territoriales. Luego alcanza el decanato de la Facultad de Filosofía y Letras de la UBA, tras veintidós en la cátedra de Geografía Física. Al mismo tiempo asume la presidencia de GAEA, Sociedad Argentina de Estudios Geográficos. En 1956, es desplazado de su cátedra, con jubilación de oficio. Dedica desde entonces mayor tiempo a escribir, lo cual le permite dar a luz su gran obra, Geografía y Unidad Argentina en la que alcanza un alto nivel de síntesis, sobre el territorio argentino.
\end{abstract}

Palabras clave: historia de la ciencia; argentina; geografía; Daus; vida institucional.

\section{Territory as a bridge between culture and politics part I: institutional itinerary of Federico Daus 19221957}

\begin{abstract}
A chronology of the institutional itinerary of Federico Daus is presented, through the schools and associations to which he belonged and through those people he worked with. Primary and secondary information was used. His years in the Universities of Buenos Aires, La Plata, as well as the changes experienced by both institutions during the ascent of Perón are characterized. His role after that is also briefly described. Initially, Daus acts in an environment linked to archeology, developing his interest in territorial issues at the same time. With the onset of Peronism, his presence evolves in a context of separation between anthropology and geography. During this transition, Daus takes office in the Ministry of Education, playing a role unrelated to territorial issues. Subsequently, he is appointed as Dean of the School of Philosophy and Literature, where he had been holding faculty positions for more than twenty years. Simultaneously, he is elected as president of GAEA, Argentine Society of Geographical Studies. In 1956 he is removed from his university chair, by means of administrative retirement. Daus has now for more time for writing, enabling him to deliver his masterpiece "Geografía y Unidad Argentina", which represents a high synthesis on the Argentine territory.
\end{abstract}

Key words: history of science; Argentina; geography; Daus; institutional life.

\footnotetext{
${ }^{1}$ Universidad de Buenos Aires. Facultad de Ingeniería. Escuela de posgrado en Ingeniería Ferroviaria. E-mail: mejlascano@yahoo.de ${ }^{2}$ Consejo Nacional de Investigaciones Científicas y Técnicas. E-mail: susanacurto@yahoo.com.ar DOI: 10.7154/RDG.2013.0026.0003
} 


\section{INTRODUÇÃO}

El conocimiento de lo propio es fuente de la participación política y del afianzamiento de la identidad nacional. Una de las claves a través de las cuales se da sentido colectivo a la realidad es el territorio. El Estado excede el término geográfico, pero sin el territorio carece de un elemento esencial (DIFRIERI, 1958). Los sucesos cotidianos y políticos vividos en común, en el espacio geográfico, así como la valoración del territorio forjan un sentido de pertenencia en la historia. El territorio confiere a la sociedad nacional vigencia como ser histórico (CHIOZZA, 1982). Al mismo tiempo, la apropiación de un espacio físico, que se realiza también a través del conocimiento generalizado, permite a un país distinguirse de otro, estar seguro de lo suyo, y hace que la cooperación con otros sea más probable (MARES, 2003). Refiriéndose al concepto de densidad nacional, Ferrer (2005) lo define a partir de la formación de estructuras, de relaciones al interior del espacio nacional, capaz de movilizar el potencial disponible. El territorio asume así simultáneamente dos caracteres: uno cultural y otro operativo.

Con esta amplitud, Federico A. Daus tuvo por vocación resaltar la importancia de lo territorial. Y por lo tanto, contribuyó a que los argentinos tuvieran sentido de sí mismos (LASCANO, 2012). Al comenzar el análisis, se tuvo por objetivo reseñar su pensamiento, pero pronto se hizo necesario indagar su itinerario institucional. Este es el tema que presentamos en este estudio. En particular, resultó necesario evaluar su inserción en el desarrollo de un pensamiento nacional que durante las décadas del '30 y el '40 tuvo múltiples expresiones, desde el pensamiento económico de Alejandro Bunge hasta el replanteo de la historia de Julio Irazusta. El mismo Daus, muchos años después, destacó la relevancia del territorio y su proyección intelectual más allá del ámbito de geógrafos y geografías. Refiriéndose al Atlas del Desarrollo Territorial de Randle, indicó que “...constituye una valiosa compensación a una historia argentina frecuentemente anecdótica, ideológica y hasta abstracta, porque insufla una cuota de realismo que no siempre ha tenido" (DAUS, 1981).

Por otro lado, Daus participó en la definición de la geografía en la Argentina. Los homenajes que recibiera en vida y luego de su deceso así lo indican: GÆEA Sociedad Argentina de Estudios Geográficos le dedica un tomo de sus Anales en el que se recopilan dedicatorias y recuerdos de colegas y discípulos (Anales GÆEA, 1979). También, consignan su necrológica diversas instituciones, como el Instituto Geográfico Militar (RANDLE, 1989), la Academia Nacional de Geografía (ARREDONDO, 1986-87; S/AUTOR, 1988-89) y el Instituto de 
Geografía de la Universidad de Cuyo (ROCCATAGLIATA, 1990). Incluso décadas antes, Fochler Haucke (1954) reseña su trayectoria. Asimismo, varias investigaciones han indagado en el rol jugado por Daus en la evolución de los estudios geográficos en la Facultad de Filosofía y Letras de la Universidad de Buenos Aires (SOUTO, 1996, QUINTERO PALACIOS, 2002) y otras han abordado el análisis de su división regional del país (BARSKY, 2000; BENEDETTI, 2010; NAVARRO FLORIA Y WILLIAMS, 2010; SALIZZI, 2012). El objetivo de este artículo es presentar el itinerario institucional y las vinculaciones de Federico Daus, en el ambiente académico de su época. Si bien será inevitable hacer referencias puntuales, su pensamiento no será abordado en esta primer capítulo.

\section{MATERIALES}

El presente estudio se estructuró sobre la base del currículum vitae de Daus, por él redactado a comienzos de la década del '70, e igualmente por él actualizado, en forma manuscrita, hacia comienzos de la década del '80. Se contó asimismo con versiones previas. Para corroborar algunos aspectos ambiguos se adoptó la información consignada en la "Guía de geógrafos argentinos" (S/AUTOR, 1950) publicada por la institución científica que Daus presidía, y que por tanto puede estimarse como exenta de errores, más probables veinte o treinta años después. Se obtuvieron las publicaciones inventariadas en este currículum vitae así como las publicaciones de las instituciones a las que estuvo vinculado. Se las analizó en forma exhaustiva, así como la bibliografía usada en ellas.

Para contextualizar dichas publicaciones, se recopilaron investigaciones existentes sobre las instituciones que las realizaron. En la bibliografía, y a lo largo del texto, se indican estas fuentes secundarias. Se propone una periodización. Asimismo, se indagó en la trayectoria de personalidades destacadas que formaron la red social científica en la que se movió Daus, tales como Félix Outes, Francisco de Aparicio, Romualdo Ardissone y Juan Keidel. Adicionalmente, se indaga en la exclusión de los geógrafos del Museo Etnográfico de la Universidad de Buenos Aires (UBA), a partir del peronismo y el rol jugado por José Imbelloni. Se aprovecha al mismo tiempo la información obtenida por los autores en entrevistas realizadas durante los últimos años, a personas que se desempeñaron con o cerca de Daus: Delia Marinelli de Cotroneo, Elena Chiozza, Raúl Rey Balmaceda, Juan Roccatagliata, Raquel Barrera de Mesiano, Patricio RANDLE, Ricardo Capitanelli y Mariano Zamorano. No se obtuvieron datos claves de todas las entrevistas, pero se consignan los entrevistados por 
haber mencionado espontáneamente a Daus en aspectos ya conocidos por el entrevistador del caso o porque guiaron en forma indirecta, al establecimiento de un orden de los sucesos. La co-autora de esta investigación conoció y trató a Daus durante casi veinte años, lo que le permitió conocer su personalidad e intereses, sirviendo ce criterio adicional para conducir razonamientos y establecer conjeturas.

Se contactó a la familia de Daus y se realizó una entrevista con Laura Daus, su hija mayor y su esposo Hermes Augusto Puyau, y con Ramón Giuntoli, yerno por parte de su segunda hija, María Blanca, ya fallecida. A raíz de nuestro interés, la familia puso a nuestra disposición el curriculum vitae. Los datos para los cuales no hay otra indicación provienen de esta fuente. Asimismo, tuvimos acceso a su biblioteca y a grabaciones de discursos correspondientes a su actuación en el Consejo Nacional de Educación. (DAUS, 1948).

Dada la larga vinculación que mantuvo con GÆEA Sociedad Argentina de Estudios Geográficos (desde aquí, G/EA), desde 1925 hasta su fallecimiento en 1988, se revisaron los siguientes documentos de asambleas de esta institución:

$\checkmark$ Libros de actas de Sesiones Ordinarias de la Junta Directiva realizadas desde 1922 a 1957. Se citan (GAEA actas seguido del número de libro con número romano, folio)

$\checkmark$ Libros de actas de Asambleas Ordinarias y Extraordinarias realizadas desde 1945 a 1957. Se citan (asamblea, Libro con números arábigos, folio).

Desde todas estas fuentes y de sus publicaciones se relevaron los viajes realizados y se inventariaron los lugares fotografiados por Daus.

\section{RESULTADOS}

\section{Durante el régimen conservador tardío}

\section{Formación e inserción institucional temprana}

Federico Alberto Daus nace en La Plata (provincia de Buenos Aires) en 1901, sexto hijo de Abdón Daus y Julia Fernández, prima del poeta Macedonio Fernández. Nieto del Capitán Daws, del ejército argentino, de origen inglés, actuante en la guerra del Paraguay. Pertenece a una familia de clase media. Es hincha del Club Estudiantes de La Plata, y muestra gran pasión por el fútbol durante toda su vida. Sus hermanos se desempeñaron en actividades comerciales. A raíz de viajes realizados en su juventud decide estudiar geografía (FOCHLER- 
HAUCKE, 1954), que por ése entonces significaba ingresar al Instituto Nacional Superior del Profesorado (INSP). Desea seguir una carrera de geografía y, según palabras del propio Daus, el profesorado "era el único lugar con cuatro años de geografía, y no sólo dos materias" (Geografía Humana y Geografía Física, de la carrera de Historia de la Universidad de Buenos Aires) (MARINELLI DE COTRONEO, comunicación oral). Algunos de sus profesores fueron Manuel Haurigot (pedagogía), Hans Sekt (biogeografía), Paul Gierth, Aníbal Anastasi (egresado del INSP en 1905), Faustino E. Juárez, Eugenio Corbet France (vicedirector del Archivo General de la Nación), Fortunato Cichero (autor de libros de texto en geografía), Juan Keidel y Franz Kühn. Finaliza sus estudios durante 1921, junto con dos compañeros, Rogelio Adet Palacios y Domingo Meccia (PENA, 2005). Inmediatamente se desempeña en la docencia secundaria, con una pausa durante 1923 al cumplir el servicio militar obligatorio. Enseña en el Instituto Susini (1922-34), el Instituto Libre de Segunda Enseñanza ILSE (19241945), en el Colegio Nacional de La Plata (1929-1945) y en el Colegio Nacional de Buenos Aires (1934-1956). Actúa también episódicamente como profesor de Historia.

En 1925 se asocia a G/EA, Sociedad Argentina de Estudios Geográficos, presentado por su fundadora, Elina González Acha de Correa Morales y por Romulado Ardissone (GAEA actas I, 135). En esta institución, donde se reúnen científicos, ingenieros y humanistas (WERNICKE, 1947; ZUSMAN, 1997), irá ganando presencia gradualmente durante las siguientes dos décadas. Su primera intervención, registrada en la Junta Directiva, es de 1930 (G/EA actas II, 245), en la que propone promover la incorporación de socios. En 1931, integra junto con Cristóbal Hicken, destacado botánico, y Federico Reichert, andinista, una comisión requerida por el Gobierno de Entre Ríos que se dirige a la ciudad de Paraná para la capacitación de profesores. Allí diserta sobre "La didáctica moderna para la enseñanza de la geografía" (GÆA actas II, 8). En 1932 integra junto a Francisco de Aparicio, arqueólogo, la comisión organizadora de la 1ra Reunión Nacional de Geografía que preside el Ing. Alfredo Galmarini. En 1934 es vocal de la junta directiva de esta asociación (GÆA actas II, 70). Cabe mencionar aquí, en el plano personal, que en 1933 fallece su primera esposa. Vuelve a casarse en 1937. A partir de 1928 forma parte del cuerpo docente de la Facultad de Filosofía y Letras de la Universidad de Buenos Aires, ya que a fines de 1927 concursa, y obtiene el cargo de Profesor Suplente en la Cátedra de Geografía Física, cuyo titular es Hans (Juan) Keidel, geólogo. Opta al cargo presentando un estudio sobre la cuenca del río Negro (DAUS 1927). Como hemos visto, en esta facultad existe otra cátedra de geografía, cuyo titular es Félix Outes, antropólogo avocado al estudio de exploradores y viajeros (ARDISSONE, 1943). Egresado de 
la carrera de medicina, Outes se vuelve autodidacta (HISPANIC SOCIETY OF AMERICA, 1920).

Es un humanista y, a diferencia de lo que sucederá en años posteriores con la arqueología, desarrolla sus trabajos desde el gabinete sin incursionar en largas salidas de campo (SALAS, 1940). Ingresa a la Cátedra de Antropología como suplente en 1908 y, en 1914, accede a la titularidad de la cátedra de Geografía Política. Esta última, originada en los planes de la Carrera de Historia, es reorientada por Outes rebautizándola "Geografía Humana", acercándola a su interés por la antropología, área en la que no puede ejercer una titularidad (BARROS, 2001).

Por iniciativa de Outes se concreta, en 1917, la creación de una Sección de Geografía, un espacio para las investigaciones adicionales a la cátedra de Geografía Humana, proyecto ya explorado antes por las autoridades de la Facultad. En 1921, esta Sección se transforma en un Instituto de Investigaciones Geográficas. Ese mismo año, Romualdo Ardissone, egresado de la carrera de Historia y docente en el INSP, se incorpora como adscripto a dicho Instituto, aunque simultáneamente obtiene la titularidad en Geografía Humana en la Universidad Nacional de La Plata, por lo que su principal ocupación estará allí y su actuación en el Instituto será muy limitada (ver bibliografía de Ardissone en DIFRIERI, 1973). Desde este Instituto Outes reúne y ordena cartografía y bibliografía geográfica, y de este modo logra reunir el acervo más importante de tal tipo, disponible en ese entonces (ARDISSONE, 1943). Poco antes del golpe militar de 1930, Outes asume la dirección del Museo Etnográfico de la UBA (BARROS, 2001), y dispone ampliar el nombre a "Etnográfico y Antropológico". Este museo, fundado dentro de la Facultad desde 1904, tiene su origen en la incorporación de colecciones arqueológicas reunidas por Juan B. Ambrosetti, antropólogo autodidacta, hijo de una familia de banqueros de Entre Ríos (CÁCERES FREYRE, 1942). Para los objetivos de este artículo, el cambio de mayor importancia fue el mandato de Outes de que el Instituto de Investigaciones Geográficas quedara bajo la tutela institucional del Museo, con su personal (ARDISSONE, 1943) y presupuesto propio (OUTES, 1931), cuyo monto estaba avocado exclusivamente a las publicaciones (OUTES, 1933). Así, el Instituto es incluido en el Museo como un "departamento" de geografía, ahora exclusivamente de Geografía Humana, lo cual define el alcance de los estudios geográficos, mantenidos en la medida en que lo justifican los principales temas, la arqueología y la antropología, cuestión que Barros (2001) denomina "la geografía de Outes como insumo en el Museo". Es así como Daus no dicta sus clases en la sede de la Facultad, sino del Museo. En este momento también se incorpora, como docente, Ardissone quien se perfila ya como el discípulo predilecto de Outes (DAUS, 1961). 
Durante la década del '30, Daus se integra al ámbito de Filosofía y Letras desde su presencia en el Museo. Desde allí accede al cargo de consejero en el Honorable Consejo Directivo de la Facultad por dos periodos (1929-30 y 1932-36). En 1934, es adscripto al Departamento de Geografía Humana, ya dirigido por Ardissone. Dos publicaciones suyas de esta etapa, se relacionan con el tema de la vivienda rural (DAUS, 1934, 1936). Dichas publicaciones integran una línea de trabajo vigente entonces y seguida por Ardissone (DIFRIERI, 1973) y, sobre todo, por Francisco de Aparicio, miembro de la Academia Nacional de Bellas Artes por designación del Poder Ejecutivo, crítico de arte y arqueólogo autodidacta (HARCOURT, 1951, DIFRIERI, 1952, S/AUTOR, 1944). Está casado con Cristina Correa Morales, una de las hijas de Elina González Acha de Correa Morales. De Aparicio llega a la UBA a comienzos de 1930 y desembarca en el Museo como Profesor Titular de Arqueología Americana. Hereda en lo sucesivo los cargos de Outes. Guber (2006) lo describe como un personaje que concentró una gran dosis de poder y caracterizado, ante todo, por su carisma. Es que De Aparicio pertenece a la elite intelectual de ese momento. Es autor de un extenso capítulo sobre los aborígenes en la Historia de la Nación Argentina publicada por la Academia Nacional de la Historia y compilada por Ricardo Levene. En 1937 integra una comisión del gobierno nacional para homenajear al Instituto de Estudios Históricos del Brasil, junto a Ravignani, Ibarguren y Levene (G/EA actas, II, 214), intelectuales encumbrados conectados con la política. Daus se integra en el grupo de amigos de De Aparicio (CHIOZZA, 2005). En GAEA, asumen ambos la organización de la Segunda Reunión Argentina de Geografía y, además, presentan socios en forma conjunta (S/AUTOR, 1935). En 1938 Daus promueve en la Junta de GAEA un proyecto de De Aparicio de colaboración con la dicha comisión relacionada con el mencionado Instituto del Brasil (GAEA, actas, II, 236).

En 1938 Daus es designado “Profesor Extraordinario" en su cátedra. En 1939 se hace socio de la Sociedad Argentina de Antropología (SAA) que De Aparicio preside (S/AUTOR, 1940). En 1940 publica su "Rasgos geográficos del nuevo mundo" (DAUS, 1940a) en la Historia de América, en varios tomos, compilada por Ricardo Levene, donde también publica De Aparicio. A comienzos de la década del '40 se forma en el Museo la asociación estudiantil “Akida" (sigla por Ardissone, (Mercedes) Costanzó, (José) Imbelloni, Daus y De Aparicio, los profesores del Museo) (LAFÓN, 2011). Daus participa, con los demás profesores y con "Akida", en viajes orientados específicamente al perfil del Museo, a ruinas arqueológicas, (S/AUTOR, 1944b; CHIOZZA, 1996; GUBER, 2006). Todos estos elementos sugieren que Daus alcanza a lo largo de estos años un posicionamiento inter pares en el Museo. Y la sociabilidad 
descrita por Guber (2006), centrada en el interés por la arqueología, parece exceder en este momento el perímetro del Museo; la noticia consignada por Chiozza (1943) en los Anales de G/EA, muestra la expansión de la antropología hacia esta asociación. Tempranamente, en 1938, Ardissone, De Aparicio y Daus, reciben de G/EA sendos subsidios para viajes de estudio, en el marco de los fondos otorgados por el gobierno Nacional, para la confección, por parte de esta institución, de la Geografía de la República Argentina (GAEA, actas, II, 231). En 1942, Daus diserta sobre la vivienda en la cordillera de Mendoza y Neuquén, en el marco de las actividades de la SAA en el Museo (S/AUTOR, 1942). En el Boletín de GAEA de enero de 1945, se destaca la contribución de los miembros del Museo durante la VI Semana de Antropología (CHIOZZA, 1945) y, en el número siguiente, se dedican varias páginas en homenaje a Ambrosetti y a Salvador Debenedetti, figuras fundadoras de la antropología argentina. G\&EA también envía representantes al acto realizado en Tilcara en 1944, en homenaje a ellos (PALESE DE TORRES, 1944; CASANOVA, 1944), y dedica dos sesiones de la IX Semana de Geografía-Congreso Nacional de Geografía (SdG-CNG), a las investigaciones del Museo (S/AUTOR, 1944c) relacionadas con el resonante descubrimiento de Tolombón, mérito de De Aparicio. En 1945 GAEA financia, junto con el Comité Nacional de Geografía, una expedición en el Norte del país, organizada y dirigida por Daus y enmarcada en las líneas de trabajo del Museo, con instrumentos facilitados por éste. A pesar de esta intensa vida intelectual en el Museo, el recorrido intelectual posterior de Daus no resultará modificado significativamente por el ambiente avocado a la arqueología y a la antropología.

\section{Exploración de líneas de trabajo alternativas}

La presencia activa de Daus en el Museo, que era el ámbito de sociabilidad de la Facultad según Guber, (2006), no debe pasar por alto la otra potencial vía de crecimiento: la cátedra de Geografía Física. Su titular Keidel (1877-1956), es doctor en geología, alemán contratado por la Dirección de Minas y Geología de la Nación a comienzos de siglo. Especializado en geología estructural, alcanza renombre internacional al contribuir a la teoría de Wegener y es considerado uno de los fundadores de la geología argentina (RAGA, 2010). En 1922, Keidel renuncia al cargo en dicha institución para abocarse por completo a la investigación y a la docencia. Realiza numerosas publicaciones, incluso algunas en co-autoría. Pero la participación de Daus en la cátedra de Keidel no produce publicaciones conjuntas (RAGA, 
2010), aunque en su producción Daus maneja la terminología y las fuentes en temas físicos (DAUS, 1938, 1946a, 1950, 1963).

En verdad, Keidel mantiene durante toda esta etapa una relación más estrecha con la Facultad de Ciencias Exactas y Naturales, a la cual se había vinculado inicialmente por un interinato en 1922 y, luego, con la titularidad en dos cátedras, desde 1927. También mantiene un vículo frecuente con la Academia Nacional de Ciencias de Córdoba y después, con el Museo de Ciencias Naturales de la Universidad de La Plata (GALMARINI, 1944; RAGA, 2010). Su presencia en Buenos Aires parece reducirse. Deja de asistir a las reuniones directivas de G/EA: durante 1929 asiste sólo a una y sólo a tres durante 1930, para reaparecer por única vez a fines de 1934. Durante todo este período llama la atención que, siendo nada más y nada menos que Vicepresidente de esta asociación, ni siquiera se consigna su nombre como "ausente con aviso", lo que sugiere que no se esperaba su asistencia. Posteriormente, asistirá a las reuniones una vez al año (G/EA actas, I y II, varias páginas), para presentar finalmente su renuncia al cuerpo directivo de esta asociación en 1937, a raíz de un desacuerdo con De Aparicio (G/EA actas II, 206-207). Ante un titular ausente, Daus es titular de facto pero sin un anclaje firme. Sus posibilidades de desarrollar estudios en geografía física, son limitadas, y ello ha quedado reflejado en su producción científica.

Daus se desenvuelve en otras líneas de trabajo. En este punto es necesario volver a los comienzos de la década de 1930. En 1934 Daus integra el Comité Nacional de Geografía, actuando como su secretario. Este organismo se crea a raíz de la visita de Emmanuel de Martonne a GAEA (GAEA actas, II, 59), en septiembre de 1933, en busca de la adhesión de la Argentina a la Unión Geográfica Internacional. La adhesión se canaliza a través del Estado Nacional (DAUS, 1952), para lo cual se crea este Comité, en el ámbito del Ministerio de Justicia e Instrucción Pública, que luego pasará a la órbita del Ministerio de Marina y Guerra al entroncar su actividad con la del Instituto Geográfico Militar (DE JORGE, 1988). Está también integrado por De Aparicio como vice-presidente. Junto con él y Alfredo Lucadamo, Director General de Estadística de la Nación, Ardissone y Daus integran la comisión especial del Comité que coordinará la composición y la edición del Anuario Geográfico Argentino, publicado en 1941. Existen pocos datos sobre las actividades de este ente, pero es pertinente consignar que, a través de él, Daus canalizó proyectos de ley (mención de De Aparicio en 1945, G/EA actas, III, 205). 
En paralelo, se incorpora al cuerpo docente de la Universidad de La Plata. En 1935 publica un artículo en el Boletín que la Universidad dedica al 50 aniversario de su Colegio Universitario, del cual Daus es profesor y Alfredo Calcagno, especialista en psicopedagogía, es rector. En esta publicación propone una primera reflexión sobre el concepto de región aplicado al territorio argentino (DAUS, 1935). El vínculo con esta universidad seguirá durante los años siguientes. En 1936 Calcagno asume como decano de la Facultad de Humanidades. En 1937 Daus acompaña a Emmanuel de Martonne en su visita a esta Universidad, invitado por Ardissone (G/EA actas, I, 190), y traduce además su exposición para ser publicada en la prestigiosa revista Humanidades. En 1939 se incorpora, como profesor suplente primero y titular después (1940), al Instituto de Investigaciones Geográficas Argentinas (CALCAGNO, 1943; S/AUTOR, 1950) en la cátedra de Geografía Política y Económica Argentina, reemplazando a Augusto Tapia, técnico agrónomo y geólogo autodidacta. Con su llegada, la bibliografía de la cátedra incorpora elementos de geografía humana, tales como la utilización de los recursos naturales, ausentes en el programa de Tapia (UNIVERSIDAD DE LA PLATA, 1941-1946). También es elegido para el Honorable Consejo Directivo de la Facultad (1942-1945).

La cátedra en La Plata parece estimular las investigaciones de Daus sobre el aprovechamiento de recursos naturales. En 1939 publica un artículo sobre el potencial agrícola y la inmigración en la Argentina (DAUS, 1939), publicado en la revista Servir de la Escuela Argentina de Estudios, institución que nuclea profesionales y científicos interesados en contribuir a la formulación de políticas públicas (OSPITAL, 2010). Se suma luego un extenso artículo en Humanidades (DAUS, 1940b) sobre los bosques del Chaco, donde los caracteriza desde el punto de vista ambiental y analiza su aprovechamiento económico y las relaciones sociales del caso. Otra contribución, referida principalmente a los recursos minerales, la realiza en el marco de uno de los cursos organizados por el Colegio Libre de Estudios Superiores (DAUS, 1940c), institución privada avocada a las humanidades, de perfil socialista, que alcanzó gran importancia durante la década del '40 (JARDÓN, 2006). Siguiendo la línea de los recursos naturales, en la VII SdG-CNG de 1942 expone un estudio sobre la extensión del cultivo de cereales en la Argentina, publicado luego en los Anales de GAEA (DAUS, 1945a). Cerrando esta etapa, cabe nombrar su exposición en la IX SdG-CNG de 1944 sobre la aplicación de una división regional al estudio de la distribución espacial de la población, publicada luego en la destacada Revista de Economía Argentina (DAUS, 1945b) de 
Alejandro Bunge y su grupo, quien había coincidido con Daus en el Comité Nacional de Geografía (LLORENS, 1947).

Durante todos estos años recorre el país, realizando numerosos viajes. En 1940 integra la Comisión de Guías del Automóvil Club Argentino. En 1943 aparece publicada su primera contribución, tarea que lo lleva a recorrer partes del Noroeste y del Sur del país. Aquí obra como autor de capítulos, junto a los que escribe Ardissone. (DAUS 1943c, 1944b y 1946b). En estas guías y en sus propias publicaciones, aparecen tomas fotográficas que realiza en las provincias y territorios nacionales de Jujuy, Salta, Tucumán, La Rioja, Catamarca, San Luis, Córdoba, Santa Fe, Chaco, Misiones, Río Negro Chubut y Santa Cruz. Es en este punto, luego de dos décadas de docencia e investigación, y luego de recorrer casi todo el país, que publica el primer volumen, parte física, de su Geografía de la Argentina para la enseñanza (DAUS, 1945).

A comienzos de 1942 se produce la jubilación de Keidel y Daus accede a la titularidad de cátedra en la UBA. En 1946 es designado vicerrector del Colegio Nacional de Buenos Aires, dependiente de la UBA, el establecimiento educativo secundario más prestigioso del país. Este mismo año asiste a la reunión en Caracas del IPGH.

\section{Ingreso a la transformación política, $1945-57$}

Cambios en el Museo Etnográfico de la UBA.

Las universidades y sus componentes se vieron inmersos en los cambios provocados por el ascenso político de Juan Domingo Perón. El medio en el que Daus actúa en la UNLP parece quedar menos afectado, sobre todo por la continuación de Calcagno en las funciones directivas de Humanidades. En cambio, sí queda irreversiblemente alcanzado el Museo Etnográfico, aún siendo un ámbito poco poblado y de resonancia menor. Daus debe tomar los pasos siguientes sorteando cambios abruptos, ya que "no militaba, no estaba afiliado" (Laura Daus, comunicación oral). En esta etapa concentra su actividad en Buenos Aires, al dejar en 1947 el dictado de su cátedra de La Plata en manos de uno de sus discípulos, Roberto García Gache y luego renunciar en 1949.

El hilo temporal debemos retomarlo sobre los sucesos que ocurren en el Museo de la UBA. Outes muere en 1939, pero su actividad se reduce antes por enfermedad. Entre su retiro por enfermedad y la llegada del peronismo, se produce la reasignación de varios cargos que 
resultarán en el nuevo escenario sobre el cual incidirán los sucesos posteriores y, sobre todo, la creación de un Instituto de Antropología, del cual pasará a depender este Museo. Ardissone, director del único Departamento/Sección abocado a los estudios territoriales, accede a la titularidad de la cátedra de Geografía Humana en la UBA en 1938 (DAUS, 1961), y accede a la vicedirección del Museo en 1940. Mientras tanto De Aparicio asume la dirección y continúa en su cátedra. El Museo se consolida como el espacio de De Aparicio.

Así las cosas, en ese mismo año José Imbelloni accede a la titularidad de la Cátedra de Antropología, donde reemplazaba, desde 1921, a Robert Lehman Nitsche y revistaba como profesor extraordinario desde 1933, también dentro del Museo. Se trata de la cátedra a la que no había podido acceder Outes. El perfil de Imbelloni excede a una estricta cronología de los estudios geográficos en la Argentina. Pero, dada la asociación entre antropología y geografía humana en la UBA, es imprescindible caracterizarlo con el objetivo de dar un marco a los sucesos siguientes ya que Imbelloni se convierte en un personaje central en la antropología de la UBA. Después de todo, la trayectoria de Daus corre superpuesta a la del Museo. Es justamente durante los años que cubriremos a continuación, que el solapamiento tiene mayores consecuencias.

Imbelloni se doctora en Italia en 1920. Recibe el premio Eduardo L Holmberg de la Academia Nacional de Ciencias Exactas, Físicas y Naturales en 1933 y, en 1937, se incorpora a la Academia Nacional de la Historia. Hacia 1946 había concretado 241 publicaciones (COMAS, 1970). Una indgación sobre sus líneas de trabajo permite comprender el destino que cabrá a los estudios geográficos del Museo. Imbelloni se avoca, ante todo, a la antropología biofísica, dedicada al estudio de las estructuras óseas o los tipos sanguíneos de las razas americanas (COMAS, 1970; GUBER, 2006; SOPRANO, 2011), de la escuela "histórico-cultural" que predominará entre 1930 y 1955 (RATIER, 2010) e incluso 1960 (LAFÓN, 2011). Este es un sector de trabajo poco conectado con la antropología de Outes y de De Aparicio, asociada a la geografía cultural de Ardissone. Es interesante notar que una revisión de la bibliografía de estas dos líneas de trabajo sugieren un ulterior interés común: las raíces pre-hispánicas de la identidad nacional. Unos la buscaban desde los componentes biológicos, como Imbelloni, y los otros desde los objetos cotidianos de las culturas americanas tales como la vivienda y las vasijas con su valor artístico, como De Aparicio. Guber (2006) consigna un episodio en el que Imbelloni se retira durante una exposición de Ardissone con una frase irónica. Durante todo este período e incluso luego de obtener la titularidad de cátedra en el Museo de la UBA, 
Imbelloni realiza sus investigaciones en el Museo de Ciencias Naturales Bernardino Rivadavia (GUBER, 2006). Es siempre ajeno a la constelación que preside De Aparicio.

A partir de 1943 serán entonces estos los posicionamientos que se verán alcanzados por la inestabilidad en la Universidad de Buenos Aires. Desde noviembre de 1943 hasta abril de 1945 se suceden ocho interventores y secretarios a cargo (S/AUTOR, Universidad de Buenos Aires, on-line). En septiembre de 1945 se produce la denominada Marcha por la Constitución y la Libertad, a la que asiste el rector de la UBA Rivarola (LUNA, 1971), quien había asumido en abril, siendo el primero en permanecer en el cargo durante más de un año. Al mismo tiempo que profesor en el Museo de la UBA, De Aparicio es presidente de la SAA. A fines de ese año, en reunión de junta, De Aparicio anuncia la suspensión de la Semana de Antropología. Propone comunicarlo mediante una declaración pública, explicando que sus “miembros más conspicuos [...] declaran no poder participar en certámenes científicos porque la intranquilidad reinante en las horas angustiosas que vivimos les niega la calma indispensable para toda labor de estudios e investigación" (actas de las SAA, citado en PODESTÁ, 2007). Ardissone (tesorero) e Imbelloni, entre otros presentes en la reunión, consideraron improcedente una declaración pública (PODESTÁ, 2007). En 1946, luego de la asunción de Perón en junio, el Ministerio de Instrucción Pública y Justicia dispone la separación de numerosos docentes, entre ellos la de De Aparicio, quien queda cesante como profesor y como director del Museo. Junto a uno de sus adjuntos, son sus únicos integrantes en ser separados.

\section{Actuación en el marco de un nuevo escenario ya consolidado}

Con la jubilación de De Aparicio, Ardissone es nombrado director interino (S/AUTOR, 2013 Museo Etnográfico). Al año siguiente, 1947, se designa como director a Imbelloni (MADRAZO, 1985), pero el Museo ya había dejado de ser el centro de la constelación; a partir de ahora pasa depender de un nuevo Instituto de Antropología que dirige Imbelloni, creado ese mismo año (MÁRQUEZ MIRANDA, 1949). Testigo de esos años, Chiozza (1996) no vacila en afirmar que "la geografía fue expulsada del Museo". En este sentido es sugestivo que, en 1947, se traslada al Etnográfico la colección antropológica del Museo Rivadavia, el anterior lugar de trabajo de Imbelloni, triplicando el número de ítems en un edificio que ya quedaba estrecho (MÁRQUEZ MIRANDA, 1949). Ardissone contaba allí con un despacho. 
A comienzos de 1947 al mismo tiempo que se crea este Instituto de Antropología, también se dispone la creación de un Instituto de Geografía (ARDISSONE, 1950) cuya dirección es asumida por Ardissone (MÁRQUEZ MIRANDA, 1949), quien la ejercerá hasta 1960 (IUT, 2005). Su funcionamiento comienza a fines de 1947 (DI BENEDETTO, 1953) con sede en la calle Viamonte. Aunque en un desamparo de facto, la geografía vuelve a depender directamente de la Facultad. Adjunta a la dirección de este nuevo Instituto queda la ya tradicional Sección de Geografía Humana del Museo. Se dispone de poco espacio (CHIOZZA, 1996). Años después, Di Benedetto (1953) se refiere al Instituto como "vestusto". Los reportes de la época consignan el establecimiento de una Sección de Geografía Física, con Daus como su director (MÁRQUEZ MIRANDA, 1949; ARDISSONE, 1950; DI BENEDETTO, 1953). En esta misma época también se crea un Instituto de Arqueología, para la otra área del Museo que excede la antropología biofísica. Lafón (2011) señala que este instituto nunca existió más allá de los papeles y consigna las limitaciones que tuvo para trabajar su director, Eduardo Casanova.

Ardissone continúa su trabajo en la Facultad y en marzo de 1947 encara una expedición al Norte del país que repite durante los veranos siguientes. En 1949 es acompañado por Mario F. Grondona, egresado del INSP en geografía, con estudios avanzados en geología en la Facultad de Ciencias Exactas y Naturales de la UBA. Mientras tanto, el puente entre geografía humana y antropología cultural parece mantenerse. En 1947, a pedido de De Aparicio, la reunión de la SAA, que se realizaba siempre en el Museo, se realiza en G/EA (G/EA actas III, 230; Podéstá, 2007). A comienzos de este año se asocia la discípula de De Aparicio, Elena Chiozza (GAEA actas III, 242), quien luego expondrá en la SdG-CNG de 1948 junto a otras figuras crecientes como Beatriz Bosch y Horacio Difrieri (GAEA asamblea 145 ). El por entonces presidente de GAEA, Pedro S. Casal, debe alejarse desde comienzos de 1948 por enfermedad y De Aparicio queda al frente como vice-presidente actuante (GAEA actas III 248) hasta octubre siguiente (GÆEA actas III 254). Ambas disciplinas siguen asociadas, pero ahora son los estudios territoriales los que en GAEA conservan una mínima estructura.

La creación del Instituto de Geografía no absorbe la actividad de Daus. A principios de 1948 asume un cargo en el gobierno nacional; en marzo de 1948 se publica su designación como Delegado Interventor del Consejo Nacional de Educación (S/AUTOR, 1948), organismo del ministerio del caso, heredado de la época de Sarmiento. La dedicación a este cargo es total; deja la vicerrectoría del Colegio Nacional de Buenos Aires; las pocas publicaciones de este momento (DAUS, 1948, 1948b) están listas antes de su ejercicio en este cargo; deja de asistir 
a las reuniones directivas de GAEA durante todo 1948 e incluso en una de ellas se resuelve realizar una visita a Daus en el Consejo (G/EA actas, III, 250), y estará ausente hasta mayo de 1949 (G/EA actas III 262). "No tengo tiempo ni para leer" dirá durante este segmento de su carrera el académico, que ahora debe ocuparse de ordenar la provisión de insumos y supervisar normas de un ente estatal. También será testigo de su final; el Consejo se suprime en 1949.

Previamente, en 1946, integra la delegación del gobierno argentino a la IV Asamblea General del Instituto Panamericano de Geografía e Historia, IPGH, que encabeza Carlos Storni. En 1947, 1949 y 1950, es el representante del país en la Sección de Geografía. Viaja sucesivamente a Caracas, Río de Janeiro y Santiago de Chile (GAEA actas III 220, 287; IV: 21). En 1949 ya no dicta su cátedra en la UNLP (S/AUTOR, 1950).

Por otra parte la actividad del nuevo Instituto de Geografía se demora. Sus dos investigadores muestran una limitada cantidad de publicaciones. Ardissone, prolífico verbalizador de la realidad, sólo registra una publicación relevante entre 1945 y 1950, en Humanidades de La Plata. Daus sólo publica en 1948 su monumental Geografía de la Argentina, con referencias bibliográficas muy anteriores a ese año (DAUS, 1948). En 1949 cesa su actividad en el Ministerio de Educación y asume dos ocupaciones que presumiblemente son tan absorbentes como su cargo gubernamental. A fines de abril de 1949, durante la asamblea general ordinaria, es elegido presidente de G/EA. Como Daus no se encuentra allí presente, son los otros candidatos, Alfredo Galmarini y el mismo presidente de la Sociedad, Pedro Casal, quienes lo proponen. Obtiene la mayor cantidad de votos, con aplauso del Presidente saliente. Pedro Casal ya lo había propuesto como vice-presidente en 1948 (G/EA actas III, 247-262; Asamblea 1, 33-49). Este mismo año, en noviembre, (COMBETTO, 1979) Daus asume como decano de la Facultad de Filosofía y Letras de la UBA.

En febrero de 1950 emprende un viaje científico a la cuenca superior del río Deseado, con el objetivo de identificar la evolución geomorfológica de los diferentes cauces próximos a la divisoria de aguas (ESCALADA, 1950). Lo acompaña García Gache, y es asistido por el Gobernador de la entonces Zona Militar de Comodoro Rivadavia. Se suma un destacado autodidacta de la antropología del Sur, Federico Escalada, de formación médico. Este viaje había sido precedido por otro, el año anterior, a lo largo de la ruta 40 en su tramo patagónico al que asisten Imbelloni y otros investigadores de la Facultad como Antonio Di Benedetto, y también Escalada (MÁRQUEZ MIRANDA, 1949). 
La actuación de Daus como decano es un punto que, aquí, enfocaremos solamente a partir de la conformación de su obra. Es sugestivo cómo Buchbinder (1997) no le atribuye mayor importancia, al mencionar a Daus tan sólo como el autor de la firma obrante al pie de medidas emanadas desde el decanato. En primer término, debe anotarse que, al contrario de lo presumible, el Instituto al que pertenece el decano no cuenta con recursos cuantiosos. Las referencias disponibles reflejan más bien lo contrario. Grondona y García Gache son auxiliares ad-honorem (S/AUTOR, 1950), y cuando, posteriormente, se consiguen remuneraciones, son muy reducidas (Kollmann, en IUT, 2005). Durante y después del decanato de Daus, el Instituto publica boletines de pocas páginas, con comentarios y breves artículos que, en su mayoría, no reflejan trabajos sistemáticos o investigaciones en campo. Tampoco se produce la creación de la carrera de geografía, la cual se encarará recién en 1953. El plan de estudios concebido ese año conserva una orientación exclusivamente cultural, incluyendo las materias de latín, griego y filosofía (ARDISSONE, 1953), mostrando más un solapamiento con las cursadas ya disponibles que una superación de la geografía como ancilla humanitas. No es Daus, sino Ardissone, quien reseña la noticia en el Boletín de G/EA. Este tema no se discute en esta sociedad (G/EA actas IV).

En 1953 Daus publica el segundo tomo de su geografía para la enseñanza media, lo cual indica un consumo de tiempo al menos durante el año precedente. Daus está "profundamente desilusionado" con el segundo gobierno de Perón (Laura Daus, comunicación personal, 2013). En este mismo año, la portada del Boletín de G/EA tiene por título "GAEA necesita mil socios", lo cual parece ser un llamado a consolidar un espacio del cual Daus es el principal referente.

En 1956 publica, a través del IPGH, la primera versión de Fisonomía Regional de la República Argentina. Esta entidad de la Organización de Estados Americanos, parece ofrecer nuevos horizontes, nuevos vínculos, al menos institucionales, para alguien que, hacia comienzos de 1950, ha subido la totalidad de los peldaños de una carrera académica. Daus es vicepresidente de la Comisión de de Geografía entre 1949 y 1957 y actúa como su presidente interino en 1955. En este ámbito establece su amistad con el geógrafo estadounidense Preston James, quien visita el Instituto de Geografía de la UBA y GAEA en junio de 1950. Viaja a los Estados Unidos en 1952 y asiste allí a reuniones del IPGH, acompañando al delegado argentino Carlos Levene y representando a G/EA en la reunión por el centenario de la Association of American Geographers. En estos años viaja a Europa (marzo-julio de 1951), GAEA actas, IV, 26-32). 
Llega así 1955 y el golpe de estado contra Perón. Daus es destituido de su cátedra y se produce su jubilación de oficio en 1956. Su hija, que realiza tareas de bibliotecaria desde hace algunos años en la Facultad, es testigo de ese proceso que afecta a sus profesores. También cesa su actividad en el Colegio Nacional de Buenos Aires y, algo más tarde, finaliza su designación para las actividades del IPGH. En 1957 ve la luz "Geografía y unidad argentina", obra ya lista durante los primeros meses de ese año, una reflexión densa sobre el rol trasversal del territorio en la conformación del Estado argentino. Este mismo año se publica una actualización de su Geografía de la Argentina, tomo VIII de la Geografía de América de la Editorial Montaner y Simón. La primera obra se dirige a espacializar la línea del tiempo en la comprensión de la identidad nacional. La segunda, a dar un sentido de conjunto a la Argentina del momento. El territorio, el centro de las dos.

La imputabilidad de peronismo también genera su alejamiento, en 1957, de la presidencia de GAEA (REY BALMACEDA, comunicación oral),que es asumida por su gran amigo, el General Carlos Levene, que acaba de finalizar su gestión al frente del Instituto Geográfico Militar. De ahora en más, la Sociedad será el centro de su actividad. Volverá a presidirla en 1963. Participará, como líbero, en actividades académicas en la UBA, en la Universidad del Salvador, en la Universidad Nacional de Cuyo y en la Escuela de Gendarmería Nacional. Dirigirá tesis doctorales. Actuará como asesor de la Cancillería. Actualizará sus textos para la enseñanza. Posteriormente incursionará en la temática del desarrollo, a la que dedicará tres libros y un largo artículo. Esta nueva etapa intelectual la desarrollará donando su tiempo desde GEAA, al margen de la inestabilidad que seguirá afectando las instituciones del país.

\section{DISCUSIÓN}

Para sintetizar la actuación de Daus, puede proponerse una apreciación preliminar de su obra académica, ya que están conectadas. A través del tiempo esta mantiene su recorrido a lo largo de una línea: conceptualizar el territorio argentino. Por un lado, en forma cultural, desde la geografía histórica compacta que decanta en 1957 con la obra "Geografía y unidad argentina" y desde la elaboración de textos escolares. Por otro lado, simultáneamente, surge una faz propositiva: qué hacer con los recursos naturales y el espacio nacional. Para llevar a cabo este programa, las herramientas disponibles son las instituciones por las que le toca pasar. Pero ocurre que en ninguna de ellas el territorio tiene carta de ciudadanía plena. Aún debe tramitarse y será clave el rol de un abogado. Es desde este rol que Daus logra exceder 
el momento que le tocó vivir. Lo excede desde el mismo momento en que elige la institución con el mejor equipo de docentes para formarse en los estudios territoriales, con el objeto de ampliar las categorías de la cultura política de una nación joven. Para Daus la visión sobre el presente también debe tener en cuenta el territorio como patrimonio histórico heredado, y como plano operativo. Su interés no está ni en los cargos ni en los papers, sino en el país mismo. Tendrá por objetivo que los argentinos incorporen lo territorial en forma operativa en sus decisiones colectivas, y al pensar su identidad.

Una geografía políticamente relevante intenta desbordar los medios académicos

La divergencia entre su producción de fines del '30 y comienzo de los '40, y la del Museo, muestra hasta qué punto hubiera sido útil a Daus recorrer el itinerario de Ardissone; llegar a la geografía luego de una inmersión en las humanidades clásicas. Con la reformas introducidas por Outes en la UBA, el ensanchamiento de la antropología es a expensas de los estudios geográficos. Daus dejó por escrito palabras de gran aprecio por el maestro de Ardissone (DAUS, 1961, 1976) pero lo cierto es que su interés estaba en la aplicación del enfoque territorial en el presente, y no en el tiempo. Esto es, más cerca de los estudios económicos y sociales de la Revista de Economía Argentina, de la Escuela Argentina de Estudios y del Colegio Libre de Estudios Superiores. Es sugestivo notar que Arturo Frondizi, quien presidirá la Argentina bajo un paradigma del desarrollo, integraba ya entonces el consejo directivo de esta última asociación, en la cual tuvo prolongada y destacada actuación (AMIUNE, 2005), lo cual muestra el significado de una contribución en Cursos y Conferencias. Daus participó entonces, dentro de las posibilidades de su contexto, en lo que daría lugar luego al desarrollismo económico. El propio contenido de estos tres artículos (DAUS 1939, 1940, 1945), así como referencias del tipo en otros, reflejan ostensiblemente una orientación a la dinamización económica sobre la base del valor agregado. La revisión de su biblioteca personal, con numerosos ítems referidos a la industria y las tecnologías aplicadas al agro, nos confirmaron la adscripción de Daus a un paradigma de lo territorial visto en el presente. La actuación posterior de muchos miembros de estas instituciones, comprueban que Daus intentó insertarse en un enfoque ya vigente. No será casual que luego dedicara tres libros al tema del desarrollo. 
No hay rastros de que estableciera un vínculo profundo con ninguna de las tres instituciones mencionadas, las cuales tuvieron en común un perfil orientado a la participación de los intelectuales en la sociedad. Es lo que también comparten los tres artículos citados. La arqueología se ocupará, en cambio, de la densidad cultural pretérita en localizaciones puntuales. Daus permanece en el Museo, se adapta, socializa, pero su trabajo abarca un programa de una geografía para grandes espacios, en su configuración actual. Teniendo en cuenta que una publicación impresa no tiene hoy la importancia que pudo tener en la década del '40, puede señalarse que existen aún en la Argentina, en medio de la apatía o la sospecha por el debate de lo propio (JITRIK, 2012), órganos intelectuales, paralelos actuales de aquellas tres publicaciones. A modo de ejemplos contemporáneos que ilustran el clima que Daus vivió en forma intensificada, encontramos en la revista Desarrollo Económico y en el Boletín de Techint, tribunas donde se publican estudios integrales sobre temas nacionales, excediendo el formato más frecuente de la columna de opinión.

La presencia de Daus en G/EA también puede entenderse como la búsqueda de ámbitos propicios para incubar nuevas ideas (CURTO et al., 2008). Tratándose de una institución específicamente geográfica, resultó ideal para quien ya a los dieciocho años tuviera claro su interés por lo territorial. En este punto cabe mencionar el debate que Daus generara durante 1938 en esta sociedad al proponer la oportunidad de un pronunciamiento institucional sobre el tema de la inmigración, de preocupación pública en la época (G/EA actas, III, 259-273). Ante la inminencia de un nuevo conflicto continental, volvía a intensificarse la emigración desde Europa pero con los Estados Unidos manteniéndose cerrados a la inmigración desde 1927. Daus ya ganaba participación en las reuniones directivas de esta sociedad y tenía margen para realizar una propuesta de este tipo. Ante la idea, el intercambio de opiniones entre los presentes se inclina por tratar el tema sobre la base de un estudio, a cargo del que ha planteado la iniciativa. Algunos meses después Daus anuncia a la junta directiva el resultado del estudio encargado, y sugiere nuevamente que GAEA haga una recomendación de carácter público. Sin restar importancia a la relación específica del tema con los estudios geográficos, la Junta consideró prudente no asumir el tema en forma institucional. GÆEA, nacida como sociedad científica que aspiraba a asumir un rol activo desde la ciencia (CURTO et al., 2008) muestra en este episodio un comportamiento análogo a las sociedades científicas tradicionales, retroalimentadas dentro de su perímetro académico. Luego de presentar estos resultados durante la III SdG-CNG (1938), Daus los publica a través de la Escuela de Estudios Argentinos. Se refiriere aquí a diferentes estudios que sobreestiman el 
potencial agrícola del país, sobre la base de un desconocimiento de su territorio. No es del todo claro por qué GÆEA rehusó publicarlo. Es interesante notar que Elina G.A. de Correa Morales incluye el episodio en su exposición de la memoria anual, en abril del año siguiente, puntualizando que la decisión de no tomar una posición pública corrió por parte de la Junta Directiva, pero aclarando que en estas deliberaciones su presidente no vota. Fue un asentimiento de la fundadora de G/EA a una geografía convertida en una disciplina socialmente relevante.

La exploración por una geografía propositiva, inserta en las demandas sociales vigentes constituyó una etapa clave en el itinerario intelectual de Daus, aún cuando no constituyó la parte o el aspecto al que más páginas dedicara. En primer lugar, lo sugiere fuertemente el contraste con el clima del Museo. Asimismo, lo indica el valor puntual de las manifestaciones tempranas que alcanzó, así como los tres libros sobre el desarrollo. Hay evidencia fragmentaria adicional en el mismo sentido, como su propuesta de una conferencia a cargo del Dr Carlos A. Alvarado, médico a cargo del Programa de Erradicación del Paludismo del Ministerio de Salud de la Nación, para la SdG-CNG (GÆA actas III 101). El paso por la UNLP, desde una cátedra de geografía económica, debió oxigenar este interés. Es cierto que las estructuras universitarias no podían acomodar un rol activo para una disciplina sin peso propio, y hubiera llevado mucho tiempo su maduración. Pero, de alguna manera, la irrupción del peronismo cercena las pocas manifestaciones incipientes. Daus deberá dedicar su tiempo a otros temas y en otros ámbitos. Desde el Boletín de GÆA se proclamará años después lo que la geografía podría aportar al planeamiento, pero ni la disciplina, ni Daus como excepción, formarán parte de los equipos que elaboraron el Plan Quinquenal. Posteriormente Daus insistirá sobre esta perspectiva, refiriéndose a la geografía aplicada (DAUS, 1960). Sin embargo, el agua corrida bajo el puente habrá sido mucha y marcadamente cultural, y Daus ya tendrá sesenta años.

Otro interrogante es la poca importancia que Daus dio a los estudios físicos, a pesar de la cátedra de la UBA. En este sentido, parece haber mayor alineamiento entre sus escritos y su acceso a la cátedra de Geografía Económica en la UNLP. Sus artículos de 1938 y 1950 muestran una gran capacidad para los estudios de geomorfología. Pero se trata de rarezas en su producción, sobre las que no insistirá después de 1950. El poco o mucho tiempo que le tocara compartir con Keidel, como se ha señalado, no constituyó una vía de crecimiento. En la nota conmemorativa, que le dedica en 1974 , no puede reconocerse el establecimiento de un vínculo con el científico alemán (DAUS, 1974); más bien se percibe una lejanía. La 
presencia de Keidel en la Facultad se construía a partir del prestigio. Sus clases transmitían una totalidad inalcanzable (DIFRIERI, 1973). El cargo de Daus, de docente suplente, corresponde entonces a una cátedra cuyo titular, Keidel, posee un limitado interés en el ámbito de Filosofía y Letras y, presumiblemente, ausente de hecho; la actividad de Keidel en la Facultad de Ciencias Exactas, las áreas lejanas del país a las que se refiere su producción durante la década del '30, sugieren su incursión en largos viajes de campo (DAUS, 1974) consistentes con la viudez del alemán desde 1916. Su presencia esporádica es igualmente consistente con su opinión sobre los estudios territoriales vertida en su discurso de apertura de la 1ra Reunión Nacional de Geografía, en el cual es pródigo con las dudas y extremadamente cauto con las certezas (KEIDEL, 1931). Estos hechos son consistentes con la dedicación a la geografía humana que tuvo Daus como investigador y, acaso, sus contribuciones a la geografía física fueron inevitables. Al fin y al cabo fue titular de ésa y no otra cátedra. Cabe agregar que, salvo por la citada referencia de Difrieri, Keidel está ausente en todo estudio referido al Museo que revisamos (CHIOZZA, 1996; GUBER, 2006; LAFÓN, 2011).

\section{La trayectoria de Daus durante el peronismo}

Puede comenzarse la discusión de esta etapa a través de su actuación durante el ascenso de Imbelloni. Ello requiere volver sobre los cambios de 1947 y la fusión del Museo con el nuevo Instituto de Antropología. No puede insistirse demasiado en el énfasis con el que Chiozza describe el momento, testigo de los sucesos junto a De Aparicio. La geografía es expulsada del Museo, pero no para ser automáticamente recibida, al menos no con las mismas condiciones, en el ámbito general de la Facultad. Creemos adecuada la alusión de Chiozza a una expulsión. La geografía no fue transferida. Fue eyectada, quedando su reinserción librada a la habilidad contingente o al capital político de Ardissone y de Daus dentro de la Facultad. La figura del Instituto constituyó la solución al alcance, la cual, debe destacarse, no surge en un momento de tranquilidad ni como resultado de un aumento de prestigio de Ardissone o de Daus. Tratándose de personajes que, con un nuevo balance de poder en la institución, no pueden retener el espacio físico que siempre habían tenido, más bien debió tener un costo; iniciar un periplo de consultas, conversaciones y pedido de favores para conseguir escritorios y despachos nuevos. Puede insistirse sobre un paralelo con el Instituto de Arqueología de Casanova, igualmente por fuera del Museo. Evidentemente, la 
arqueología también es expulsada del Museo. Todo aquello que excede la antropología de Imbelloni es acreedor de un Instituto, pero poco más allá del plano administrativo. La partida de Daus a un cargo gubernamental es sólo explicable en un contexto de deterioro de las condiciones previas. Cabe enfatizar que este cargo gubernamental nada tuvo que ver con los temas propositivos desarrollados en sus estudios, ni con sus funciones en el Comité Nacional de Geografía, ni con sus contactos en G/EA. Años después, también Casanova hace su partida, concentrando su trabajo en la restauración del Pucará de Tilcara, sin posibilidad de formar discípulos (LAFÓN, 2011).

Combetto (1979) consigna que la creación del Instituto de Geografía de la UBA fue a instancias de Daus. Respecto de esta afirmación cabe preguntarse qué visibilidad hubiera podido tener para Imbelloni, que detentaba un poder discrecional, una disciplina tan sólo auxiliar de esa arqueología también excluida del nuevo Instituto de Antropología. A juzgar por el rol sólo secundario de los estudios territoriales, y por su reacción durante una exposición de Ardissone, Imbelloni hubiera podido pasar por alto esta ancilla humanitas, que hubiera podido continuar existiendo en sus dos cátedras. Es dable pensar que Daus, con mayor cintura política que Ardissone, gestionara a través de la Facultad o de Imbelloni la preservación, en alguna forma, del espacio que poseían los estudios geográficos. Esta habría sido la intervención de Daus. Los sucesos posteriores no sugieren que la creación del Instituto fuera fruto de una intervención del futuro decano, presumiblemente ya poderoso, para aprovechar el momento y crear un espacio propio. Creado el Instituto, no asume su dirección $y$, apenas en funcionamiento, reduce al mínimo su presencia o incluso la interrumpe del todo: en 1948 se aboca por completo al CNE. Por lo demás, tampoco lo dirige luego de terminada su etapa al frente al Consejo. Podría insistirse algo más en este aspecto, ya considerando el tiempo ejercido en el decanato, y el irresistible aura de poder que hubiera podido otorgar la plena ciudadanía a esa geografía "anclaje de la antropología" (GUBER, 2006). Por ejemplo, en estos años la SdG-CNG-no se realiza en la UBA. Mientras Daus está en el cargo, se refiere a la necesidad de formar geógrafos profesionales (DAUS, 1951), en franco contraste con el programa de materias de 1953; una geografía humana cargada de erudiciones, más próxima a la serena abundancia de Ardissone.

Creemos que estos elementos permiten afirmar que la vinculación de Daus con el peronismo fue limitada. Al igual que en momentos previos, las circunstancias sirven para seguir abogando por su persistente interés en conceptualizar el territorio. Incluso el clima peronista le sirvió a tal fin, aun cuando suele ser presentado como un artefacto que absorbió todos los 
aspectos de la vida del país sin dejar nada al margen. Pero no se encuentran elementos que sugieran que este momento político coloca a Daus en una posición de poder que permitirá la institucionalización de la disciplina en medio de las dos áreas de conocimiento que disputan, cada una con su peso propio, los escasos recursos. Hacia fines de los '50, el dictado de la carrera aún se realiza desde un Departamento de Antropología (LAFÓN, 2011). Si Daus contribuye al perfilamiento de la geografía ante las demás disciplinas, lo hace más eficazmente desde su personalidad y su producción, que desde sus posibilidades políticas. No obsta a esto el alineamiento retórico que podemos encontrar en dos de sus discursos, grabados, como funcionario público; aquí Daus se refiere al año de 1947 como el de la "segunda independencia": la económica (Argentina, 1948). Se trata de una manifestación del propio régimen político, ya que la selección de los conceptos está fuera del control real del orador, por la naturaleza del cargo desde donde pronuncia estas ideas, sólo parcialmente superpuestas con su propio pensamiento (LASCANO y CURTO, 2013).

Algunos sucesos posteriores a 1947 muestran que, a pesar de haber quedado fuera del Museo, tanto arqueólogos como geógrafos, no interrumpen la comunicación entre ambos, tanto de los colegas como de los discípulos de De Aparicio. La reunión de 1947 de la SAA es llevada a cabo en G/EA y luego, Ardissone expone en la Semana de Antropología de diciembre de 1950 (ARDISSONE y GRONDONA, 1952). Pero es posible que Daus no estuviera en una posición de poder para restablecer, en la Facultad de la UBA, la posición privilegiada (LAFÓN, 2011) del grupo del Museo. En este sentido, la muerte de De Aparicio debió constituir, adicionalmente, un fuerte golpe para todos sus antiguos integrantes.

En los finales del peronismo, la separación de sus cargos de 1956, que podría ser interesante desde el punto de vista del entramado de linajes entrantes y salientes (GUBER, 2006) es, al menos, difícil de explicar, aun considerando la visibilidad que alcanzara como decano. Lo que Daus plausiblemente quiso, pero efectivamente no hizo, muestra un encumbramiento académicamente prestigioso pero políticamente débil y, sería coherente suponer, que estuvo por sobre las posibilidades de sus vinculaciones. En este sentido podríamos decir que no poseyó un acceso irrestricto a las élites de un momento u otro; ni al exquisito Levene de la Academia, antes del peronismo, ni a los historiadores de la Facultad. En todo el material revisado no hemos encontrado una sola referencia a una participación de suya en el Instituto de Historia de la Facultad, ya sea en sus actividades o a través de un relacionamiento con sus profesores. Con el peronismo en el poder tampoco pueden identificarse vínculos con Imbelloni. Su acceso al decanato permanece como una incógnita, 
aunque podría atribuirse a su carácter de figura con perfil político pero ajena, tanto al sector de los historiadores como al sector de la antropología, ahora vigente en la Facultad. Queda como hipótesis el rol de Daus como candidato de compromiso entre dos polos cuyos poderes están en plena reconfiguración.

Por último, y para cerrar el análisis de su paso por un cargo de connotaciones intensas, el decanato no parece reportarle mayores beneficios a largo plazo. El balance desde 1947, al contrario, parece ser negativo. Si bien es donde había alcanzado una articulación sólo parcial con sus intereses, con la salida- expulsión del Museo, Daus pierde la pertenencia a un ámbito con características sobresalientes: por un lado por su presupuesto, es cierto, pero sobre todo por el grupo humano cohesionado, a juzgar por la viva impresión que dejó entre quienes se formaron allí (CHIOZZA, 1996; LAFÓN, 2011). Es difícil pensar que, sin fondos para trabajar, con poco espacio, en un edificio vetusto, con el capital de trabajo reducido al perímetro de la cátedra, el paso al nuevo Instituto de Geografía fuera una mejora. Con la caída del peronismo, de poco valdrán el "mérito" de la titularidad de cátedra obtenida en forma previa 1 1945, la virtud de no obtener poder con el peronismo y el reivindicable hecho de perder con Imbelloni en 1947. Acaso prevalece el valor simbólico del decanato y Daus es, nuevamente, expulsado a pesar de encontrarse en una posición igual, o peor, que en 1942. Federico Daus desarrolló su carrera intentando maximizar las posibilidades de su época, poniéndose en contacto con múltiples espacios. Desarrolló una valoración del territorio, como patrimonio, como eje en común de los argentinos. El territorio del que habla también es el de quienes son sus interlocutores. El crecimiento intelectual, en el país de la primera mitad del siglo XX, fue general: se ha hablado de la generación del centenario. El aporte de Daus se insertó en un movimiento mayor que, entre otras coas, también demandó comprender el territorio. Políticamente, esta profusión intelectual, sobre todo enfocada en lo propio, decantó en conjugación con otros factores sociales, también en el peronismo, aunque puede argüirse que nutrió al desarrollismo.

La Argentina es un país joven, $y$, además, rejuvenecido con el aporte inmigratorio. Daus se ha referido a este aspecto cultural de nuestra formación. $Y$ ha dicho que un elemento propio del resultado social, sea cual sea, es el territorio (DAUS, 1957). Esta reflexión final de Geografía y Unidad Argentina establece una vinculación de planos de análisis que suelen ser abordados por canales académicos y científicos separados. Más recientemente, desde un punto de vista que integra la historia y la economía, Ferrer (2005) se ha referido al traslado de la notable creatividad que la sociedad argentina ha expresado en el plano cultural, hacia 
al plano económico y social. Aquí se inscribió la trayectoria de Daus quien intentó transitar desde el plano de la cultura, desde los estudios territoriales, hacia la política, y lo hizo con los medios a su alcance, desde una disciplina naciente, joven, como la propia Argentina de entonces.

\section{AGRADECIMIENTOS}

Al revisor anónimo que con sus observaciones posibilitó la mejora de este escrito. A Laura Daus por responder nuestras preguntas y ayudarnos con la corrección final del texto. A Ramón Giuntoli, por facilitarnos el currículum vitae y el acceso a la biblioteca de Federico Daus. A GÆEA, Sociedad Argentina de Estudios Geográficos por permitirnos revisar extensivamente sus libros de sesiones y de actas.

\section{REFERENCIAS}

AMIUNE, J. M.; La ideología del desarrollo y el desarrollo de la ideología. In: Jornada sobre desarrollo nacional en homenaje al Dr. Arturo Frondizi. Org. por Hugo Carassai. Buenos Aires. Fundación $\quad$ Frondizi. $2005 . \quad$ Disponible en http://www.fundacionfrondizi.org.ar/libro06.htm acceso 15/12/2012

ARDISSONE, R.;Félix Outes. Anales GAEA 7:145-146, 1943

. Las publicaciones del Instituto. In: Daus, F. "La supuesta captura del río Fénix". Buenos Aires. Instituto de Geografía. Universidad de Buenos Aires. 1950.

ARDISSONE, R., GRONDONA, M.; La instalación aborigen en Valle Fértil. Publicación del Instituto de Geografía Serie A, no 18. Buenos Aires. Universidad de Buenos Aires. 1952.

ARGENTINA. Ministerio de Justicia e Instrucción Pública.; (1948). Discursos del señor interventor del Consejo Nacional de Educación. Grabaciones en disco de vinilo. 1948.

ARREDONDO, R.; Presentación del Académico de Número Doctor D. Servando Ramón Manuel Dozo. Anales de la Academia Nacional de Geografía 11: 97-98, 1986-1987.

BARROS, C.; La antropogeografía en Buenos Aires. Terra Brasilis Nova Sèrie on line 3, 2001.

BARSKY, A.; Auge y ocaso de la "Regiones geográficas argentinas" de Federico Daus. In: Actas del II Encuentro Internacional, Humboldt, Mar del Plata, Argentina. 2000.

BENEDETTI, A.; Quebrada de Humahuaca: ¿hoya, unidad fisiográfica, región geográfica, ambiente o lugar? Estudio bibliográfico sobre la toponimia y el pensamiento regional argentino. Registros 7: 111-138. 2010.

BUCHBINDER, P.; Historia de la Facultad de Filosofía y Letras de la Universidad de Buenos Aires. Buenos Aires. Editorial Universitaria de Buenos Aires. 1997. 
CÁCERES FREYRE, J.; El sabio doctor Juan. B. Ambrosetti. Revista Geográfica Americana XVIII, no 111: 345-348.

CALCAGNO, A.; Creación del Instituto de Investigaciones Geográficas Argentinas. Anales GÆA VII: 137-140. 1943.

CASANOVA, E. Discurso de homenaje a J.B. Ambrosetti y S. Debenedetti. Boletín GAEA 14: 2324. 1944

CHIOZZA, E.; Sociedad Interamericana de Antropología y Geografía. Anales GAEA VII: 489492. 1943.

. La "Antigua Provincia de los Diaguitas" fué el tema de la VI Semana de Antropología. Boletín GÆEA 13: 1-6. 1945.

. La República Argentina. In: Atlas Total de la República Argentina. Atlas Político, 1-2 (Organizado por Elena Chiozza). Buenos Aires. Centro Editor de América Latina. 1982

. Discurso de presentación evocando a Francisco de Aparicio. Anales de la Academia Nacional de Geografía 20: 37-40. 1996.

_. Entrevista con Guillermo Cicalese. 2005. Disponible en nulan.mdp.edu.ar/1446/1/01268.pdf acceso 5/12/12.

COMBETTO, R.; Homenaje al Dr. Federico Daus. Anales G/EA XVII: 15-16. 1979.

COMAS, J.; José Imbelloni (1895-1967). Anales de Antropología UNAM 7: 290-291. 1970.

CURTO, S.; JÁREGUI, B.; ESCUELA, M.; LASCANO, M.; PENA, H.; La fundación de GAEA Sociedad Argentina de Estudios Geográficos - 1922. Boletín G/EA 126: 80-136. 2008.

DAUS, F.; Geografía Regional. Boletín de la Universidad Nacional de La Plata 19, 1, 8997.1935.

. La hidrografía de la región endorreica del Noroeste argentino. Anales GAEA VI: 207-225. 1938.

. El poblamiento de la Argentina. Servir 32: 3-24.1939.

- Rasgos geográficos del Nuevo Mundo. In: Historia de América (organizado por Ricardo Levene),Tomo I, 3-80. Buenos Aires. Jackson. 1940a.

. Los bosques del Chaco. Humanidades (La Plata) 28: 139-201. $1940 \mathrm{~b}$.

. El medio geográfico como fuente de riqueza. Cursos y conferencias 17, no 8: 21302149. 1940c.

. El panorama geográfico del mundo moderno. Revista Geográfica Americana XIX 114: 127-136. 1943a. $\overline{1943 b .}$

. Los recientes estudios geográficos en la Argentina. Acta Americana 1, no 1: 83-87. 
. Patagonia, descripción general. In: Guía de Viaje Zona Sur. Buenos Aires. Automóvil Club Argentino. 1943c.

. Población de los oasis ricos y de los oasis pobres de la región árida argentina. Humanidades (La Plata) 29: 53-63. 1944a.

- Rasgos generales del Noroeste. In: Guía de Viaje Zona Noroeste. Buenos Aires. Automóvil Club Argentino. 1944b.

. Extensión de la zona cereal argentina. Anales GAEA VII: 377-382. 1945a.

. García Gache, R. Distribución de la población argentina por regiones geográficas. Revista de Economía Argentina 44, no 324: 294-296. 1945b.

. Geografía de la Argentina I: parte física. Buenos Aires. Estrada. 1945c.

. Viaje de estudios a las sierras de Culampajá. Boletín GAEA 14: 19-21. 1945d.

- Comarcas del Nordeste argentino. In: Guía de Viaje Zona Nordeste. Buenos Aires. Automóvil Club Argentino. 1946a.

- Morfografía general de las Ilanuras argentinas. In: G/EA Geografía de la República Argentina (Organizado por Elina González Acha de Correa Morales) t III, 115-198. 1946b.

. Trashumación de montaña en Neuquén. Anales GÆA VIII: 383-426. 1948.

- La supuesta captura del río Fénix. Buenos Aires. Publicación del Instituto de Geografía Serie A, no 1. 1950.

- Discurso de apertura de la XV Semana de Geografía. In: Actas de la XV Semana de Geografía. Mendoza. Universidad Nacional de Cuyo. 1951.

- Reseña sobre historia de los conocimientos geográficos de la Argentina. Geográfica IPGH XI-XII, 1-5. 1952.

. Geografía y unidad argentina. Buenos Aires. Nova. 1957.

. Argentina. Geografía de América. Tomo VIII. Barcelona. Montaner y Simón. 1957.

. La geografía aplicada. Boletín G/EA 49: 4-8. 1960.

. Romualdo Ardissone. Boletín de Estudios Geográficos Universidad Nacional de Cuyo VIII, no 32: 91-96. 1961.

. Juan Keidel. Anales GAEA XVI: 103-105. 1974.

. Prólogo. In: Rey Balmaceda, R. Geografía histórica de la Patagonia. Buenos Aires. Cervantes. 1976.

. Presentación. In: Randle, P.H., Atlas del desarrollo territorial de la Argentina. Buenos Aires. OIKOS. 1981 
DAUS, F., VIDIRI, F.; Observaciones sobre el estado de la vivienda en el Nordeste argentino. La habitación popular 12: 33-39. 1936.

. Notas sobre la vivienda patagónica. La habitación popular 14: 33-39. 1938.

DI BENEDETTO, A.; El Instituto de Geografía de la Universidad de Buenos Aires. Boletín GÆA 30: 21-22. 1953.

DE JORGE, C.; Evolución de las ciencias en la República Argentina, tomo X, 1923- 1972: Geografía. Buenos Aires. Sociedad Científica Argentina. 1988.

DIFRIERI, H.; Necrológica. Francisco de Aparicio. Boletín G/EA 29: 20. 1952.

. El territorio y las fronteras. In: Summa de Geografía, T. I, 173-213. Buenos Aires. Peuser. 1958.

. Romualdo Ardissone. In: Homenaje a Romualdo Ardissone, 7-22. G/EA. Buenos Aires. 1973.

ESCALADA, F.; Exploraciones en la cuenca del Deseado. Misión Daus. Revista de Gendarmería Nacional VI, no 72: 21-29. 1950.

FERRER, A.; Arturo Frondizi y la construcción de la densidad nacional. In: Jornada sobre desarrollo nacional en homenaje al Dr. Arturo Frondizi. Org. por Hugo Carassai. Buenos Aires. Fundación 2005.2 Drondizi. 20 en http://www.fundacionfrondizi.org.ar/libro06.htm $\quad$ Disponible en http://www.fundacionfrondizi.org.ar/docs/FERRER.doc acceso 14/12/12

FOCHLER-HAUCKE, G.; Figuras del pensamiento americano. Federico Daus. Humanitas 4: 347-351. 1954.

GALMARINI, A.; Homenaje al doctor Juan Keidel. Boletín GAEA 11: 2-5. 1944.

G/EA; Libro de Actas, T I . 1922-1931.

GÆA; Libro de Actas, TII inédito. 1931-1940.

G/EA; Libro de Actas, T III inédito. 1941-1950.

GÆA; Libro de Actas, TIV inédito. 1950-1971.

G/EA, Libro de Actas de Asambleas, T1

GÆA, Libro de Actas de Asambleas, T2

GUBER, R.; Linajes ocultos en los orígenes de la antropología social de Buenos Aires. AVÁ 8, 1-35. 2006.

GUBER, R., BONNIN, M.; LAGUENS, A.; Tejedoras, topos y partisanos. prácticas y nociones acerca del trabajo de campo en la arqueología y la antropología social en la Argentina. Relaciones de la Sociedad Argentina de Antropología XXXII: 381-406. 2007. 
HARCOURT, R.; Francisco de Aparicio (1893-1951). Journal de la Société des Américanistes $40: 246-250.1951$.

HISPANOC SOCIETY OF AMERICA.; Félix Outes. In: Argentines of today. New York. Jackson. 1920.

IUT, V.; La formación del campo profesional de geógrafos en la Argentina 1947-1975. Tesis de Licenciatura. Buenos Aires. Departamento de Geografía Universidad de Buenos Aires. 2005.

JARDÓN, M.; La producción del discurso psicológico en Cursos y Conferencias revista del colegio libre de estudios superiores de 1931 a 1960. Facultad de Psicología - UBA Anuario de Investigaciones 14: 147-155. 2006

JITRIK, N.; Victorino. Diario Página 12, 22/02/12. 2012

KEIDEL, J.; Discurso de apertura. 1ra Reunión Nacional de Geografía. Anales GAEA IV, 1: 7787. 1931.

LAFÓN, C. R.; La arqueología y el Museo Etnográfico de la Facultad de Filosofía y Letras de la Universidad de Buenos Aires. Introducción de R. Guber. Corpus. Archivos virtuales de la alteridad americana 1, 2: 1-25. 2011.

LASCANO, M.; Realismo político y territorio. In: Historia y política en Julio Irazusta (organizado por Marcelo R. Lascano). Buenos Aires. La Ley. 2012.

LASCANO, M.; CURTO, S.; El territorio como puente entre la cultura y la política, parte II. El pensamiento de Federico A. Daus 1922-1957. En prensa. 2013.

LLORENS, E.; Alejandro E. Bunge. Anales G/EA VIII: 525-527. 1947.

LUNA, F.; El ‘45. Buenos Aires. Sudamericana. 1971.

MADRAZO, G.; Determinantes y orientaciones de la antropología argentina. Boletín del Instituto Interdisciplinario de Tilcara 1: 13-56. 1985.

MÁRQUEZ MIRANDA, F.; Actividades de las "ciencias del hombre" en la Argentina. Bulletin de I'Institute Français d' Etudes Andines 1: 212-223. 1949.

MARES, D.; Conflictos limítrofes en el hemisferio occidental. Análisis de su relación con la estabilidad democrática, la integridad económica y el bienestar social. In: Conflictos territoriales y democracia en América latina (organizado por Domínguez, J). Buenos Aires. Siglo XXI Editores. 2003.

NAVARRO FLORIA, P.; WILLIAMS, F.; La construcción y problematización de la regionalidad de la Patagonia en las geografías regionales argentinas de la primera mitad del siglo $\mathrm{xx}$. Scripta Nova Revista Electrónica de Geografía y Ciencias Sociales. 2010.

OSPITAL, S.; Intelectuales, científicos y naturalistas en busca de alternativas para la Argentina. La Escuela de Estudios Argentinos y la revista Servir. 1936 - 1943. VIII Congreso de Sociología Rural, Porto de Galinhas. 2010. Disponible en http://www.alasru.org/wpcontent/uploads/2011/09/GT19-Maria-Silvia-Ospital.pdf acceso 11/01/2013 
OUTES, F.; Noticia. En "Misión al río del Sauce". Buenos Aires. Publicaciones del Instituto de Investigaciones Geográficas. Serie A no 12. 1933.

PALESE DE TORRES, A.; Hacia el Pucará de Tilcara. Boletín GÆEA 14: 20-22. 1944.

PENA, H.; Aportes para la historia del departamento de geografía del Instituto Superior Joaquín V. González. Boletín G/EA 123: 4-24. 2005.

PODESTÁ, M.; 70 años en la vida de la sociedad argentina de antropología. Relaciones de la Sociedad Argentina de Antropología XXXII: 9-32. 2007.

QUINTERO PALACIOS, S.; Geografías Regionales en la Argentina. Imagen y valorización del territorio durante la primera mitad del siglo XX. Scripta Nova VI, 127. 2002. available on-line at http://www.ub.edu/geocrit/sn/sn-127.htm\#n23 retrieved 21/12/12

RANDLE, R.; Personalidad y Obra de Federico A. Daus. Revista del IGM 5: 10-12. 1988.

RATIER, H.; La antropología social argentina: su desarrollo. Revista del Colegio de Graduados en Antropología IX, 17-46. 2010.

ROCCATAGLIATA, J.; Federico A. Daus 1901-1988. Boletín de Estudios Geográficos Universidad Nacional de Cuyo 24, 86: 7-14. 1990

SALAS, A.; Félix Outes. Boletín de la Sociedad Argentina de Antropología 1: 245-246. 1940.

S/AUTOR; (S/año). Breve historia de la Universidad de Buenos Aires http://www.uba.ar/institucional/contenidos.php?id=91 acceso 22/01/2013

S/AUTOR; Sesiones de la Junta Directiva. Boletín G/EA 4: 32. 1935.

.Memoria 1939-1940. Boletín de la Sociedad Argentina de Antropología 1: 270. 1940.

. Memoria 1941-1942. Boletín de la Sociedad Argentina de Antropología 3: 290. 1942. 1944a.

. Distinciones hechas por el poder ejecutivo a nuestros consocios. Boletín GAEA 9: 8. . Notable descubrimiento arqueológico en Tolombón. Boletín GÆEA 8: 8. 1944b.

. La IXa Semana de Geografía. Boletín GÆEA 12: 1. 1944c.

. Asumió el cargo de Delegado Interventor el profesor Federico Alberto Daus. El Monitor de la Educación Común 901-904: 93. 1948.

. Guía de geógrafos de la República Argentina. Boletín GAEA 27: 25-42. 1950.

- La geografía en la Facultad de Filosofía y Letras. Boletín de Estudios Geográficos Universidad Nacional de Cuyo 7, 29: 290-291. 1960.

. Académico Dr. Federico A. Daus. Su Fallecimiento. Anales de la Academia Nacional de Geografía 12-13: 17-18. 1988-89. 
. Directores. Sitio Web del Museo Etnográfico y Antropológico, de la Universidad de Buenos Aires. 2013. http://museoetnografico.filo.uba.ar/elmuseo/museo-elmuseo.html. Acceso 22/01/13

SALIZZI, E.; Continuidades y rupturas en el discurso regional argentino: el proceso de construcción conceptual de la Pampa. Mundo Agrario 12, 24: 1-37. 2012.

SOPRANO, G.; La producción académica e inserción institucional universitaria de Fernando Márquez Miranda (décadas de 1930 y 1960). In: actas, X Congreso Argentino de Antropología Social. Noviembre. Facultad de Filosofía y Letras UBA. 2011.

SOUTO, P.; Geografía y Universidad. Institucionalización académica y legitimación científica del discurso territorial en la Universidad de Buenos Aires. Territorio 8, Buenos Aires. Instituto de Geografía, Universidad de Buenos Aires. 1996.

UNIVERSIDAD DE LA PLATA.; Programas, curso de 1940-45. La Plata. Facultad de Humanidades y Ciencias de la Educación. 1941-1946.

WERNICKE, E.; G/EA Sociedad Argentina de Estudios Geográficos en el escenario nacional y en el exterior. Boletín G/EA 7: 7-8. 1943.

ZUSMAN, P.; Una geografía científica para ser enseñada. La Sociedad Argentina de Estudios Geográficos (1922-1940). Documents d'Análisi Geográfica 31: 171-189. 1997.

Artigo recebido em 05/07/2013.

Artigo aceito em 06/09/2013. 